\title{
The long noncoding RNA Synage regulates synapse stability and neuronal function in the cerebellum
}

\author{
Fei Wang ${ }^{1} \cdot$ Qianqian Wang ${ }^{1} \cdot$ Baowei Liu ${ }^{1} \cdot$ Lisheng Mei $^{1} \cdot$ Sisi $\mathrm{Ma}^{2} \cdot$ Shujuan Wang ${ }^{3} \cdot$ Ruoyu Wang ${ }^{1,4}$. \\ Yan Zhang ${ }^{5} \cdot$ Chaoshi Niu $^{6} \cdot$ Zhiqi Xiong $^{7} \cdot$ Yong Zheng ${ }^{3} \cdot{\text { Zhi Zhang } \mathbb{D}^{1} \cdot \text { Juan Shi }}^{2} \cdot$ Xiaoyuan Song $\mathbb{D}^{8}$
}

Received: 2 July 2020 / Revised: 7 March 2021 / Accepted: 10 March 2021 / Published online: 24 March 2021

(c) The Author(s), under exclusive licence to ADMC Associazione Differenziamento e Morte Cellulare 2021. This article is published with open access

\begin{abstract}
The brain is known to express many long noncoding RNAs (lncRNAs); however, whether and how these lncRNAs function in modulating synaptic stability remains unclear. Here, we report a cerebellum highly expressed lncRNA, Synage, regulating synaptic stability via at least two mechanisms. One is through the function of Synage as a sponge for the microRNA miR$325-3$ p to regulate expression of the known cerebellar synapse organizer $C b \ln 1$. The other function is to serve as a scaffold for organizing the assembly of the LRP1-HSP90AA1-PSD-95 complex in PF-PC synapses. Although somewhat divergent in its mature mRNA sequence, the locus encoding Synage is positioned adjacent to the Cblnl loci in mouse, rhesus macaque, and human, and Synage is highly expressed in the cerebella of all three species. Synage deletion causes a full-spectrum cerebellar ablation phenotype that proceeds from cerebellar atrophy, through neuron loss, on to synapse density reduction, synaptic vesicle loss, and finally to a reduction in synaptic activity during cerebellar development; these deficits are accompanied by motor dysfunction in adult mice, which can be rescued by AAV-mediated Synage overexpression from birth. Thus, our study demonstrates roles for the lncRNA Synage in regulating synaptic stability and function during cerebellar development.
\end{abstract}

These authors contributed equally: Fei Wang, Qianqian Wang, Baowei Liu

Edited by M. Bianchi

Supplementary information The online version contains supplementary material available at https://doi.org/10.1038/s41418021-00774-3.

Xiaoyuan Song

songxy5@ustc.edu.cn

1 Hefei National Laboratory for Physical Sciences at the Microscale, CAS Key Laboratory of Brain Function and Disease, School of Life Sciences, Division of Life Sciences and Medicine, University of Science and Technology of China, Hefei, Anhui, China

2 National Laboratory of Medical Molecular Biology, Institute of Basic Medical Sciences, CAMS and PUMC, Beijing, China

3 State Key Laboratory of Proteomics, Beijing Proteome Research Center, National Center for Protein Sciences (Beijing), Beijing Institute of Lifeomics, Beijing, China

4 Graduate School of Biomedical Sciences, University of Texas MD Anderson Cancer Center and UTHealth, Houston, TX, USA

5 Stroke Center \& Department of Neurology, The First Affiliated Hospital of USTC, Division of Life Sciences and Medicine,

\section{Introduction}

Cerebellar development is an important process for regulating the onset of a variety of motor and non-motor behaviors [1]. The cerebellar cortex is composed of three layers: the molecular layer, the Purkinje cell (PC) layer, and the granule cell (GC) layer, from outermost to innermost

University of Science and Technology of China, Hefei, Anhui, China

6 Department of Neurosurgery, The First Affiliated Hospital of USTC, Division of Life Sciences and Medicine, University of Science and Technology of China, Hefei, Anhui, China

7 Institute of Neuroscience, State Key Laboratory of Neuroscience, CAS Center for Excellence in Brain Science and Intelligence Technology, Chinese Academy of Sciences, Shanghai, China

8 MOE Key Laboratory for Membraneless Organelles and Cellular Dynamics, Hefei National Laboratory for Physical Sciences at the Microscale, CAS Key Laboratory of Brain Function and Disease, School of Life Sciences, Division of Life Sciences and Medicine, University of Science and Technology of China, Hefei, China 
[2]. The GC layer consists of small and densely packed excitatory granule neurons that make up the vast majority of neurons in the cerebellum and the brain [3]. The PC layer harbors the largest GABAergic inhibitory PCs, as well as Bergmann glial cells (BGCs), which are mainly located around PCs $[4,5]$. The formation of mature neurons and stabilized synapses during development is a prerequisite for proper nervous system functionality, which require synaptic proteins. For instance, CBLN1, highly expressed in cerebellar GCs, is a synaptic protein crucial for organization of parallel fibers (PFs, axons of the GCs) and PCs [6, 7]. Similarly, LRP1, a postsynaptic transmembrane protein, forms a complex with postsynaptic N-methyl-D-aspartate receptors through PSD-95 (a postsynaptic density protein) to modulate synaptic transmission and synaptic plasticity [8-12]. However, much remains unclear about the mechanism of synaptic stability.

Long noncoding RNAs (lncRNAs) are transcripts longer than 200 nucleotides that do not translate into functional proteins (except in some cases forming small, potentially functional peptides). Like many protein-coding mRNAs, many lncRNAs also exhibit strong specificity in their spatiotemporal expression [13]. Many lncRNAs function in neurodevelopment. For example, the nervous system-specific IncRNAs Evf2 and Pinky regulate neural development $[14,15]$. The nuclear-enriched GM12371 lncRNA is a prolific transcriptional regulator and is critical for synapse function in hippocampal neurons [16]. Nevertheless, the neurobiological functions of the overwhelming majority of IncRNAs remain enigmatic compared with protein-coding genes. Importantly, it remains unclear whether and how lncRNAs modulate synaptic stability. The Gm2694 lncRNA (alias AK082312) was originally found to have enriched expression in the mouse cerebellar cortex [17]. The Gm2694 lncRNA (alias linc1582) was later found to be associated with neuroectoderm differentiation [18]. Recently, Gm2694 (alias Trincr1) was documented to regulate FGF/ERK signaling and the self-renewal of embryonic stem cells [19]. Although with all of these studies, whether and how Gm2694 functions in the cerebellar synapse was mysterious.

Here, we studied this synapse-functional cerebellum lncRNA, particularly three isoforms of $G m 2694$, which we designated as Synage, and which is distributed in the cytoplasm and synapses of cerebellar cells. We showed that Synage modulates the expression of the synaptic protein CBLN1 in GCs and contributes to preventing cerebellar atrophy and motor defects. We also found that Synage mediates the assembly of the LRP1-HSP90AA1-PSD-95Synage complex in PCs to regulate synaptic stability. Our study presents long-term in vivo data demonstrating the developmental functions of Synage lncRNA and reveals the mechanisms underlying its regulation of synaptic stability and cerebellar development.

\section{Materials and methods}

\section{Animal models}

Wild-type (WT) BALB/C and C57BL/6 mice were purchased from the Vital River Laboratories (Beijing, China) and housed in a humidity and temperature-controlled room under a reverse 12-h dark-light cycle. Mice were provided with food and water ad libitum under standard conditions. All procedures were in accordance with the guidelines of and approved by the University of Science and Technology of China Animal Resources Center and University Animal Care and Use Committee (Permit Number: USTCACUC1801015).

The sgRNAs were designed to target exon 1 and the end of last exon of Synage, thus excising almost the entire Synage locus, while avoiding the shared promoter region with $C b \ln 1$, to produce Synage knockout (KO) mice using the CRISPR-Cas9 system. Subsequently, genomic DNA was extracted and used to identify mouse genotypes with three pairs of specific primers for polymerase chain reaction (PCR) amplification and sequencing. In this study, the WT offspring of Synage heterozygous KO mice were used as the control group for Synage homozygous mice. BIOGLE Company provided F1 heterozygous KO mice. The sgRNA, shRNA, and genotyping primer sequences are listed in Supplementary Table S3.

\section{Reverse transcription and quantitative PCR (RT- qPCR)}

Total RNAs were extracted using TRIzol reagent (Ambion, 15596) following the manufacturer's instructions. RNasefree DNase (Promega, M6101) was used to remove residual DNA. Reverse transcription was performed using the commercially available reverse transcription system (Promega, A5001). The real-time qPCR experiments were performed on a Bio-Rad CFX96 qPCR system according to the manufacturer's instructions (Vazyme, Q111-03). Gene expression levels were calculated relative to the reference gene GAPDH. The RT-qPCR primer sequences are listed in Supplementary Table S3.

\section{$5^{\prime}$ - and $3^{\prime}$-Rapid amplification of CDNA ends (RACE)}

Both 5'- and $3^{\prime}$-RACE experiments were performed following the manufacturer's instructions (Invitrogen, 18374058, 18373-019). Briefly, $5^{\prime}$ and $3^{\prime}$ gene-specific primers (GSPs) were designed to perform amplification of cDNA ends using the RACE-Ready cDNA as a template. The cDNA products were then inserted into a pRACE vector. Both PCR screening with GSPs and Sanger sequencing were further performed to identify the full-length cDNA of the target gene. 


\section{Western blot}

Mouse tissue was dissected on ice. The whole cerebellum was then transferred to a homogenizer and added to 500- $\mu$ l RIPA buffer (50-mM Tris-HCl (pH 7.4), 150-mM NaCl, 1-mM EDTA, $1 \%$ Triton X-100, 1\% SDS, $1 \%$ sodiumdeoxycholate, fresh proteinase inhibitor cocktail, PMSF) for every $20 \mathrm{mg}$ of samples. After homogenization and constant agitation at $4{ }^{\circ} \mathrm{C}$ for $2 \mathrm{~h}$, each sample was centrifuged at $14,000 \mathrm{~g}$ for $10 \mathrm{~min}$ at $4{ }^{\circ} \mathrm{C}$. The supernatant was aspirated and placed in a fresh tube kept on ice. The lysate was then diluted with $2 \mathrm{X}$ SDS loading buffer (125-mM Tris-HCl (pH 6.8), 4\% SDS, 20\% glycerol, $0.2 \%$ bromophenol blue, $10 \% \beta$-mercaptoethanol) and boiled at $100{ }^{\circ} \mathrm{C}$ for $5 \mathrm{~min}$ and stored at $-80^{\circ} \mathrm{C}$. The subsequent Western blot protocol was performed as described previously [20].

\section{Co-immunoprecipitation (co-IP)}

The whole homogenized mouse cerebellum was lysed in 1$\mathrm{ml}$ NET-N buffer (20-mM Tris- $\mathrm{HCl}(\mathrm{pH} 8.0), 125-\mathrm{mM}$ $\mathrm{NaCl}, 1-\mathrm{mM}$ EDTA, 0.5\% NP-40, 10\% glycerol, fresh proteinase inhibitor cocktail, PMSF). The lysate was incubated at $4{ }^{\circ} \mathrm{C}$ for $1.5 \mathrm{~h}$ on a rotating platform and subsequently treated with ultrasonication. The sonicated lysate was cleared by centrifugation at $14,000 \mathrm{~g}$ for $10 \mathrm{~min}$ at $4{ }^{\circ} \mathrm{C}$, then the supernatant was pre-cleared with Protein $A / G$ Magnetic Beads (Thermo, 88803). Next, the supernatant was incubated with specific antibodies (HSP90AA1 (Proteintech, 13171-1-AP), or LRP1 (Abcam, ab92544), PSD95 (Abcam, ab2723), or control IgG (Cell Signaling Technology, 5873/8726)) overnight on a rotating platform at $4{ }^{\circ}$ C. Subsequently, Protein A/G Magnetic Beads were added to the supernatant for $2 \mathrm{~h}$ at $4{ }^{\circ} \mathrm{C}$ under gentle rotation. The beads were pelleted and washed three times with ice-cold NET-N buffer. The sample was then boiled in $1 \mathrm{X}$ SDS loading buffer at $100{ }^{\circ} \mathrm{C}$ for $5 \mathrm{~min}$ before Western blot detection.

\section{Synage overexpression and co-IP}

Cells $\left(1 \times 10^{6}\right)$ were transfected with Synage overexpression plasmid (V12-PLKO.1) and then cultured in a 6-cm dish. Forty-eight hours later, the overexpressed Synage cells were pelleted at $500 \mathrm{~g}$ for $5 \mathrm{~min}$. After washing twice with phosphate-buffered saline (PBS), cell pellets were resuspended in $0.7-\mathrm{ml}$ NET-N buffer with fresh proteinase inhibitor cocktail and PMSF, and incubated at $4{ }^{\circ} \mathrm{C}$ with rotation for $60 \mathrm{~min}$. The lysate was isolated by centrifugation at $14,000 \mathrm{~g}$ for $10 \mathrm{~min}$. The co-IP protocol was performed as described above.

\section{RNA immunoprecipitation (RIP)}

The whole homogenized mouse cerebellum was crosslinked in 1\% formaldehyde (Sangon Biotech, A5019120500 ) for $10 \mathrm{~min}$ on a rotating platform. To stop the reaction, $0.125-\mathrm{M}$ glycine was added for $10 \mathrm{~min}$ and the sample was pelleted at $2000 \mathrm{~g}$ for $5 \mathrm{~min}$. Then the cell pellet was incubated in NET-N buffer for $1.5 \mathrm{~h}$ at $4{ }^{\circ} \mathrm{C}$. The lysate was sonicated and centrifuged at $14,000 \mathrm{~g}$ for $10 \mathrm{~min}$. Next, the supernatant was divided into two samples and incubated with specific antibodies and control IgG overnight on a rotating platform at $4{ }^{\circ} \mathrm{C}$. Next, the supernatant was incubated with Protein A/G Magnetic Beads for $2 \mathrm{~h}$ at $4{ }^{\circ} \mathrm{C}$ under gentle rotation. Beads were recovered and washed three times with NET-N buffer. The beads were resuspended in proteinase $\mathrm{K}$ buffer $(100-\mathrm{mM} \mathrm{NaCl}, 10$-mM Tris$\mathrm{HCl}(\mathrm{pH} 7.0$ ), 1-mM EDTA, $0.5 \%$ SDS, $20-\mu \mathrm{g} / \mathrm{ml}$ proteinase $\mathrm{K}$ ) for $20 \mathrm{~min}$ at $56^{\circ} \mathrm{C}$. The remaining beads were used for RNA extraction and RT-qPCR analysis to identify interacting RNA segments according to the manufacturer's instructions.

\section{In vivo RNA pull-down-mass spectrometry (MS)}

The in vivo RNA pull-down-MS assay was performed as previously described [21]. Briefly, the whole homogenized mouse cerebellum was cross-linked in $1 \%$ formaldehyde for $10 \mathrm{~min}$, followed by $0.125-\mathrm{M}$ glycine quenching for $5 \mathrm{~min}$. The sample was pelleted at $2000 \mathrm{~g}$ for $5 \mathrm{~min}$. Cross-linked cell pellets were lysed in lysis buffer $(50-\mathrm{mM}$ Tris- $\mathrm{HCl}(\mathrm{pH}$ 7.0), 10-mM EDTA, 1\% SDS, fresh proteinase inhibitor cocktail, PMSF, Murine RNase inhibitor) and solubilized by sonication. The supernatant was incubated with biotinylated antisense oligo probes in hybridization buffer (750-mM NaCl, $1 \%$ SDS, 50-mM Tris-Cl pH 7.0, 1-mM EDTA, $15 \%$ formamide, fresh proteinase inhibitor cocktail, PMSF, Murine RNase inhibitor) at $37^{\circ} \mathrm{C}$ overnight under gentle rotation. M-280 Streptavidin beads (Invitrogen, $11206 \mathrm{D})$ were added to the lysis buffer and incubated at $37{ }^{\circ} \mathrm{C}$ for $30 \mathrm{~min}$ with rotation. The RNA-binding protein complex components were washed five times using wash buffer (2X SSC, $0.5 \%$ SDS, fresh PMSF). For protein elution, beads were resuspended in protein elution buffer (7.5-mM, N-2-hydroxyethylpiperazine-N-2-ethanesulfonic acid (HEPES, pH 7.5), 15-mM EDTA, 0.15\% SDS, 75-mM $\mathrm{NaCl}, 0.02 \%$ sodium-deoxycholate) at $25^{\circ} \mathrm{C}$ for $20 \mathrm{~min}$ and at $65^{\circ} \mathrm{C}$ for $10 \mathrm{~min}$. Twenty-five percent total volume TCA (trichloroacetic acid) was added to the clean eluent, and mixed proteins were precipitated at $4{ }^{\circ} \mathrm{C}$ overnight. Subsequently, proteins were pelleted at $16,000 \mathrm{~g}$ at $4{ }^{\circ} \mathrm{C}$ for $30 \mathrm{~min}$. The supernatant was removed, and the protein pellet was washed with cold acetone and pelleted again at 
$16,000 \mathrm{~g}$ at $4{ }^{\circ} \mathrm{C}$ for $30 \mathrm{~min}$. The pellet was left to air-dry for $1 \mathrm{~min}$ and stored at $-80{ }^{\circ} \mathrm{C}$ before $\mathrm{MS}$.

\section{Biotin-mmu-miR-325-3p pull-down}

The procedure for miRNA pull-down was performed as previously described [22]. In brief, for biotin-labeled miRNA pull-down experiments, 200-pmol biotin-labeled mmu-miR-325-3p (GenePharma) were transfected into $2 \times$ $10^{6}$ HT-22 cells. After $24 \mathrm{~h}$, the cells were lysed in lysis buffer (20-mM Tris (pH 7.4), 100-mM KCl, 0.3\% NP-40, 5- $\mathrm{mM}_{\mathrm{MgCl}_{2}}$, fresh proteinase inhibitor cocktail, PMSF, Murine RNase inhibitor). Streptavidin magnetic beads (Invitrogen, 11206D) were added to the cell lysate and incubated at $4{ }^{\circ} \mathrm{C}$ for $4 \mathrm{~h}$ with rotation. The M-280 Streptavidin beads were washed three times using lysis buffer. RNA bound to the M-280 magnetic beads was isolated using TRIzol LS reagent (Invitrogen, 10296028) and quantified by RT-qPCR.

\section{Electrophoretic mobility shift assays (EMSAs)}

EMSAs were performed using the Chemiluminescent EMSA Kit according to the manufacturer's protocol (Beyotime, GS009). Briefly, whole cerebellum tissue lysate was prepared in cytoplasmic lysis buffer (1\% Triton X-100, 25-mM Tris- $\mathrm{HCl}$ (pH 7.4), 40-mM KCl) with fresh proteinase inhibitor cocktail, PMSF, and RNase inhibitors. The cerebellum lysate was centrifuged at $14,000 \mathrm{~g}$ for $10 \mathrm{~min}$, after which the supernatant was treated with M-280 Streptavidin beads (Invitrogen, 11206D) to pre-clear the cytoplasmic extract (CE). Biotin-labeled Synage RNA probes (150 ng) were incubated with 14- $\mu$ g CE. Unlabeled Synage RNA probes $(7500 \mathrm{ng}$ ) were used as a competitor. The reaction was separated by native 6\% PAGE gels and transferred onto nylon membranes. Biotin signals were detected by chemiluminescence.

\section{Immunofluorescence (IF)}

The mice were anesthetized and intracardially perfused with PBS. The brain was dissected and fixed in $4 \%$ paraformaldehyde (PFA) overnight and dehydrated with a sucrose gradient. The frozen sagittal sections (thickness, $8-10 \mu \mathrm{m})$ were washed three times with $1 \mathrm{X}$ PBS. The sections were permeabilized by $0.1 \%$ Triton X-100 for 30 min. Tissue sections were incubated in $3 \%$ bovine serum albumin (BSA) for $1 \mathrm{~h}$ and then incubated with primary antibodies overnight at $4{ }^{\circ} \mathrm{C}$. Tissue sections were washed with $1 \mathrm{X}$ PBS three times and subsequently incubated in secondary antibodies for $1-2 \mathrm{~h}$ at room temperature (RT). Tissues were washed with $1 \mathrm{X}$ PBS three times and incubated for $2 \mathrm{~min}$ with Hoechst 33342 for nuclear counterstaining. The immunostained tissues were visualized using an FV1200 confocal microscope system (OLYMPUS, Japan). The cerebellum sections with the largest area in each mouse were selected for cerebellar developmental phenotype analysis. The following primary antibodies were used: PSD-95 (Abcam, ab2723), LRP1 (Abcam, ab92544), HSP90AA1 [Alexa Fluor 647] (Novus, NBP177682AF647), CBLN1 (Abcam, ab181379), CalbindinD28k (Proteintech, 14479-1-AP, 66394-1-1g), Gdf10 (Santa Cruz, sc-390046). The following secondary antibodies were used: goat anti-rabbit IgG H\&L (Alexa Fluor 488, Abcam, ab150077), Alexa Fluor594-conjugated goat anti-mouse $\operatorname{IgG}(\mathrm{H}+\mathrm{L})$ (Proteintech, SA00006-3), and goat anti-rabbit IgG H\&L, F (ab') 2 Fragment (Alexa Fluor 647 conjugate, Santa Cruz, 4414).

\section{In vitro transcription}

The cDNA of mouse Synage (n424059) was cloned into pcDNA3.1 vector. The plasmid was linearized to produce a DNA template, and full-length sense or antisense RNAs were transcribed in vitro using T7 RNA polymerase (Invitrogen, 18033019) or MAXIscript SP6 Transcription Kit (Invitrogen, AM1330) in combination with biotinylated NTPs (Roche, 11685597910). In vitro transcribed RNAs were further used for FISH assays in cerebellar sections directly as described below, or for EMSAs as described above.

\section{Fluorescence in situ hybridization (FISH)}

All solutions were prepared using RNase-free reagents and diethylpyrocarbonate-treated double deionized water. Fresh-frozen brain sections $(10 \mu \mathrm{m})$ were fixed in $4 \%$ PFA for $10 \mathrm{~min}$ and washed with 1X PBS three times. Sections were digested with $1 \mu \mathrm{g} / \mathrm{ml}$ of proteinase $\mathrm{K}$ buffer for 20 $\mathrm{min}$ and incubated in acetylation solution for $10 \mathrm{~min}$. The sections were placed in the hybridization buffer $(50 \%$ formamide, 5X SSC, $0.3-\mathrm{mg} / \mathrm{ml}$ tRNA) without biotinylated probes for $5 \mathrm{~h}$ at $\mathrm{RT}$ and incubated in the hybridization solution with corresponding RNA probes $(200 \mathrm{ng} / \mathrm{ml})$ for $12-14 \mathrm{~h}$ at $70^{\circ} \mathrm{C}$. After hybridization, the slices were washed once in $5 \mathrm{X} \mathrm{SSC}$ at $70{ }^{\circ} \mathrm{C}$ and washed twice in $0.2 \mathrm{X}$ SSC for $30 \mathrm{~min}$ at $70^{\circ} \mathrm{C}$. Sections were further incubated with streptavidin antibody and other primary antibodies for $2 \mathrm{~h}$ at RT. Tissue sections were washed with 1X PBS three times and subsequently incubated in secondary antibodies for $1 \mathrm{~h}$ at RT. Tissues were washed three times with 1X PBS and incubated with Hoechst 33342 for nuclear counterstaining, then visualized using an FV1200 confocal microscope system (OLYMPUS, Japan). The following primary antibodies were used: Streptavidin, Alexa Fluor ${ }^{\mathrm{TM}} 555$ Conjugate (Thermo Fisher, S21381), Anti-PSD-95 antibody 
(Abcam, ab2723), Anti-LRP1 antibody (Abcam, ab92544), and HSP90 alpha Antibody [Alexa Fluor 647] (Novus, NBP1-77682AF647). Sections were then incubated in the following secondary antibodies: goat anti-rabbit IgG H\&L (Alexa Fluor ${ }^{\oplus 88)}$ (Abcam, ab150077, 1:1000) and Alexa Fluor594-conjugated goat anti-mouse $\operatorname{IgG}(\mathrm{H}+\mathrm{L}$ ) (Proteintech, SA00006-3, 1:500). Biotin-labeled short specific probes for Synage lncRNA were used in RNA-FISH assays in $\mathrm{C} 8$-D1A cell line, lacZ probes were used as negative controls (NCs).

\section{Transmission electron microscopy (TEM)}

Mice were deeply anesthetized with $8 \%$ chloral hydrate, and then perfused and prefixed via the heart with 1X PBS and $4 \%$ PFA. The brain tissue was removed and immediately fixed in $4 \%$ PFA for $1-2 \mathrm{~h}$ at RT. The target sample (200$\mu \mathrm{m}$ thick, $1 \mathrm{~mm}^{2}$ ) was obtained using a vibratome and disposable biopsy punches (Robbins instruments, RBP-10). The sample was fixed with $2 \%$ PFA and $3 \%$ glutaraldehyde in 0.1-M phosphate buffer and $1 \%$ osmium tetroxide in 0.1 $\mathrm{M}$ cacodylate buffer ( $\mathrm{pH}$ 7.4). The sample was then dehydrated using graded ethanol, followed by embedding with EPON 812. Ultra-thin sections (60-nm thick, $\left.200 \mu \mathrm{m}^{2}\right)$ were obtained and stained. Finally, electron micrographs were taken at final magnification of $\times 11,000$ and $\times 30,000$. All electron micrographs were analyzed by ImageJ plugins.

\section{Electrophysiology}

Mice were deeply anesthetized with pentobarbital sodium ( $2 \%$ w/v, i.p.) and intracardially perfused with $\sim 20-\mathrm{ml}$ icecold oxygenated modified N-methyl-D-glucamine artificial cerebrospinal fluid (NMDG ACSF) that contained 93-mM $\mathrm{N}$-methyl-D-glucamine (NMDG), 2.5-mM KCl, 1.2-mM $\mathrm{NaH}_{2} \mathrm{PO}_{4}, 30-\mathrm{mM} \mathrm{NaHCO} 3,20-\mathrm{mM}$ HEPES, 25-mM glucose, 2-mM thiourea, 5-mM Na-ascorbate, 3-mM Na-pyruvate, $0.5-\mathrm{mM} \mathrm{CaCl}, 10-\mathrm{mM}_{2} \mathrm{MgSO}_{4}$, and 3-mM glutathione (GSH). The $\mathrm{pH}$ of the ACSF was 7.3-7.4, and osmolarity was $300-305 \mathrm{mOsm} / \mathrm{kg}$. Coronal slices $(250 \mu \mathrm{m})$ were sectioned at $0.18 \mathrm{~mm} / \mathrm{s}$ on a VT1200s vibrating microtome (Leica, Germany). The brain slices were initially incubated in NMDG ACSF for $10-12 \mathrm{~min}$ at $33{ }^{\circ} \mathrm{C}$, followed by HEPES ACSF that contained 92-mM NaCl, 2.5-mM KCl, 1.2-mM NaH${ }_{2} \mathrm{PO}_{4}, 30-\mathrm{mM} \mathrm{NaHCO}_{3}, 20-\mathrm{mM}$ HEPES, 25-mM glucose, 2-mM thiourea, 5-mM Naascorbate, 3-mM Na-pyruvate, 2-mM $\mathrm{CaCl}_{2}, 2-\mathrm{mM}$ $\mathrm{MgSO}_{4}$, and 3-mM GSH (pH 7.3-7.4, osmolarity $300-305 \mathrm{mOsm} / \mathrm{kg}$ ) for at least $1 \mathrm{~h}$ at $28^{\circ} \mathrm{C}$.

The brain slices were transferred to a slice chamber (Warner Instruments, USA) for electrophysiological recording and were continuously perfused with standard ACSF that contained 124-mM NaCl, 2.4-mM CaCl $2,5-\mathrm{mM}$
$\mathrm{KCl}, \quad 1.3-\mathrm{mM} \quad \mathrm{MgSO}_{4}, \quad 26.2-\mathrm{mM} \quad \mathrm{NaHCO}_{3}, \quad 1.2-\mathrm{mM}$ $\mathrm{KH}_{2} \mathrm{PO}_{4}$, and 10-mM glucose (pH: 7.3-7.4, osmolarity: $300-305 \mathrm{mOsm} / \mathrm{kg}$ ) at $2.5-3 \mathrm{ml} / \mathrm{min}$ at $32{ }^{\circ} \mathrm{C}$. The temperature of the ACSF was maintained by an in-line solution heater (TC-344B, Warner Instruments, USA). Patch pipettes (3-5 M $\Omega$ ) were pulled from borosilicate glass capillaries (VitalSense Scientific Instruments Co., Ltd., Wuhan, China) with an outer diameter of $1.5 \mathrm{~mm}$ on a four-stage horizontal puller (P1000, Sutter Instruments, USA). For recording miniature inhibitory postsynaptic current (mIPSCs), the pipettes were filled with intracellular solution that contained 145-mM CsCl, 10-mM EGTA, 10-mM HEPES, 2-mM $\mathrm{MgCl}_{2}, 2-\mathrm{mM} \mathrm{CaCl}_{2}, 2-\mathrm{mM} \mathrm{Mg-ATP}$, and 5-mM QX-314. The osmolarity of the solution was adjusted to 285-290 $\mathrm{mOsm} / \mathrm{kg}$, and the $\mathrm{pH}$ was adjusted to 7.2 with $\mathrm{CsOH}$. 6,7dinitroquinoxaline-2,3(1H,4H)-dione $(10 \mu \mathrm{M})$ was added to eliminate excitatory components, and $1-\mu \mathrm{M}$ tetrodotoxin (TTX) was added to the bath solution to eliminate spontaneous action potentials. For recording miniature excitatory postsynaptic current (mEPSCs), the pipettes were filled with an intracellular solution that contained 130-mM K-gluconate, 2-mM $\mathrm{MgCl}_{2}$, 5-mM $\mathrm{KCl}$, 0.6-mM EGTA, 10-mM HEPES, 2-mM Mg-ATP, and 0.3-mM Na-GTP (osmolarity: 290-300 $\mathrm{mOsm} / \mathrm{kg}$ ), and the $\mathrm{pH}$ was adjusted to 7.4 with $\mathrm{KOH}$. To abolish the inhibitory synaptic transmission, 50$\mu \mathrm{M}$ PTX and 1- $\mu \mathrm{M}$ TTX were added in the standard ACSF. All electrophysiological recordings were Bessel-filtered at $2.8 \mathrm{KHz}$ and sampled at $100 \mathrm{KHz}$. All electrophysiological data were analyzed by pCLAMP software version 10.7 (Axon Instruments, USA).

\section{Virus injection}

AAV-EGFP-control or AAV-EF1 $\alpha$-Synage virus (BrainVTA, China) was injected into the cerebellum of randomly assigned neonatal WT and Synage KO mice. Briefly, neonatal mice were anesthetized on ice for $4 \mathrm{~min}$ and placed into a stereotaxic frame. An injecting pipette containing 300-400 $\mathrm{nl}$ of the AAV was injected into the cerebellum, then the mice were placed on a heating pad until they woke up. The whole procedure was completed in $<20 \mathrm{~min}$. The injected pups were then transferred to the mother for care after they recovered normal movement.

\section{Rotarod test}

Rotarod tests were performed during the light phase using a rotarod training system (XR1514, Xinruan, Shanghai, China). Before the training sessions, mice were placed in the behavioral test room at least $30 \mathrm{~min}$ in advance in order to adapt to the environment. Mice were then habituated to stay on the stationary rod for $2 \mathrm{~min}$. Subsequently, mice were placed on a rotarod apparatus that accelerates 


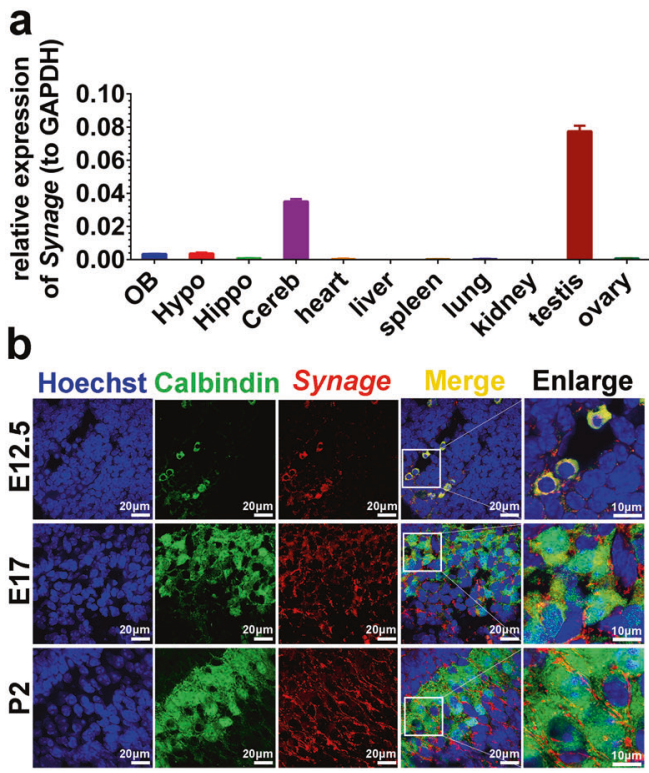

Fig. 1 Synage IncRNA is mainly distributed in the cytoplasm and dendrites of cerebellar neurons. a Relative expression levels of Synage in four brain regions (OB olfactory bulb, hypo hypothalamus, hippo hippocampus, cereb cerebellum) and seven organs (heart, liver, spleen, lung, kidney, testis, and ovary) of adult mice detected by RTqPCR. b, c RNA-FISH of Synage (using an antisense probe, red) and

4-40 rpm for $5 \mathrm{~min}$. Most mice fell before $40 \mathrm{rpm}$. Mice were trained in three trials for 20-min intervals per day for 2 consecutive days. The rotarod was cleaned between individual tests. Latency of falling and total running distance were recorded automatically. The mice that did not move during the rotarod test were not analyzed.

\section{Balance beam test}

The balance beam tests were performed as previously described [23]. Briefly, the beam apparatus included 120$\mathrm{cm}$ beams with a flat surface of 10 or $8-\mathrm{mm}$ width placed on two brackets $50 \mathrm{~cm}$ above the table top. On training days, each mouse crossed the center $80 \mathrm{~cm}$ of a $10-\mathrm{mm}$ beam three times, and subsequently an 8-mm beam three times. Mice were trained in six trials in 10-min intervals per day for 2 consecutive days. On the test day, the time to cross the center $80 \mathrm{~cm}$ of each beam was measured and recorded. The beams were cleaned with $75 \%$ ethanol before each trial and between each mouse. The mice that did not move during the balance beam test were not analyzed.

\section{Quantification and statistical analysis}

All experiments were independently repeated at least three times with similar results. All statistical analyses were conducted using GraphPad software. To assess the statistical significance of a difference between two treatments, we
C

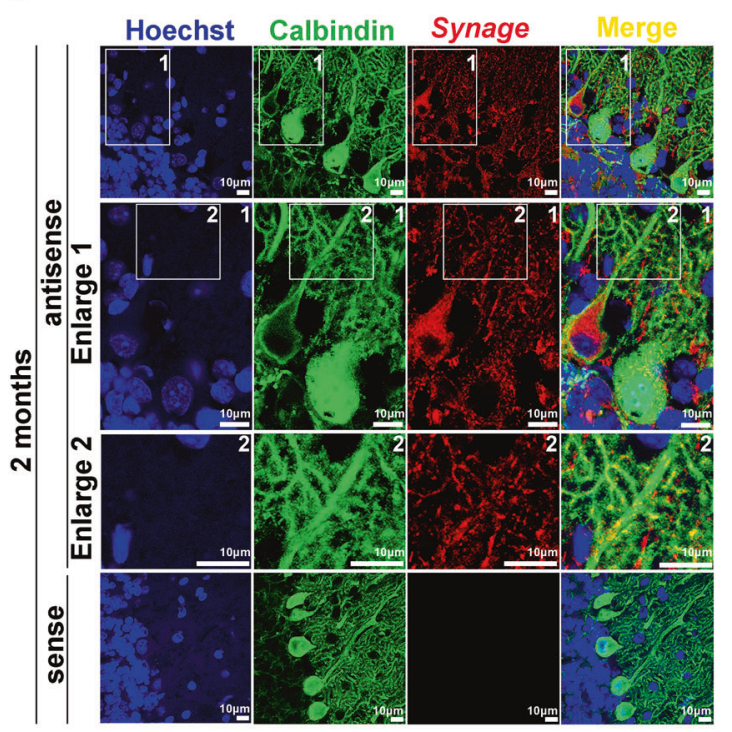

immunofluorescence of Calbindin (green, a Purkinje cell marker) in the cerebellar sections from E12.5 (embryo at 12.5 days), E17, P2 (the second day after birth) (b), and 2-month-old (c) wild-type (WT) mice. RNA-FISH using sense probe of Synage was a negative control. Nuclei were stained with Hoechst 33342 (blue). The numbers (1 and 2) show the enlarged areas.

used unpaired, two-tailed Student's $t$ tests. We used twoway ANOVA followed by Tabular's multiple comparisons for multiple groups. Statistical significances are shown as $* P<0.05,{ }^{*} P<0.01,{ }^{*} * * P<0.001$, and data are shown as the mean \pm SEM.

\section{Results}

\section{Conserved Synage IncRNA is highly expressed in the cerebellum from mouse to human}

To study cerebellar-relevant lncRNAs, we selected a highly expressed lncRNA, Synage, from our ribo-minus RNASequencing (rmRNA-Seq) data in adult mouse brains (BIG Data accession number CRA001819). Synage is synonymous with the $G m 2694$ gene, particularly three isoforms of Gm2694-n424059, n285242, and n264625. We examined the abundance and tissue specificity of Synage transcript across different organs and brain regions by RT-qPCR. The results showed that Synage was specifically enriched in the cerebellum and testis of adult mice (Fig. 1a). In the current study, we focused on the function of Synage in the cerebellum.

We first performed RNA-FISH using a biotin-labeled Synage antisense RNA probe in the C8-D1A cell line (astrocyte type I cloned cell line from 8-day postnatal mouse cerebella [24]) and mouse cerebellum sections at 
several developmental stages, including E12.5, E17, P2, and 2 months. Synage was mainly distributed in the cytoplasm of C8-D1A cerebellum cells (Fig. S1), and was specifically distributed in the Purkinje cell precursors (PCPs) at E12.5, while at E17, P2, and 2 months, it was localized primarily in cytoplasm and dendrites of cerebellar cells, including PCs (Fig. 1b, c).

Synage-homologous genes (LOC106995009 in rhesus macaque, and RP11-491F9.1 in human) were conserved in terms of their locations in the genomes of mouse, rhesus macaque, and human (adjacent to the Cblnl gene) (Fig. S2a-c). Similar to Synage lncRNA in mouse [17], its homologous lncRNAs exhibited cerebellum-specific expression in rhesus macaque [25] and in human tissues according to a recent study [26] and GTEx project database (dbGaP Accession phs000424.v8.p2) (Fig. S2d). Taken together, Synage lncRNA is conserved in its genomic location (adjacent to the $C b \ln 1$ gene) and in its distribution specificity in the cerebellum among mouse, rhesus macaque, and human.

According to our rmRNA-Seq in mouse brains (Fig. S3a), the expression level of n424059 (one of the Synage isoforms) was the highest, followed by n 285242 (one of the Synage isoforms) and TCONS_00072254 (Fig. S3b). Although the expression trend of Synage isoforms detected by RT-qPCR was not completely consistent with that of rmRNA-Seq (Fig. S3c-g), n424059 and n285242 were relatively highly expressed in both rmRNASeq and RT-qPCR. In addition, the 5'- and $3^{\prime}$-RACE experiments using n424059-specific primers (Fig. S4a-d) revealed that Synage is $663 \mathrm{nt}$ in length, consistent with the length of n424059 and with cDNA sequencing conducted in this study (Fig. S4e). Therefore, our data support that n424059 is a typical sequence for Synage RNA; we thus used the n424059 IncRNA sequence for our following in vitro and in vivo overexpression experiments.

\section{Synage KO mice show significant cerebellar atrophy and neuronal loss during cerebellar development}

We generated Synage KO mice with sgRNAs targeting Synage exon 1 and the $3^{\prime}$ end of the last exon coupled with the CRISPR-Cas9 system, ablating most Synage locus, while avoiding deletion of the putative promoter region shared with Cbln1 (Fig. 2a). F1 mice that carried heterozygous (HT) alleles were confirmed by PCR-based genotyping (Fig. S5a). Homozygous mice were obtained by crossing these HT mice, and again confirmed by PCR (Fig. S5a) and sequencing (Fig. S5b). We used RT-qPCR (Fig. 2b) and FISH (Fig. S5c) to verify the absence of the Synage transcript in Synage KO mice compared with WT mice.
Between WT and Synage KO mice, there were no significant changes in the body appearance (Fig. S5d), body weight (Fig. S5e, f), or brain weight (Fig. S5g, h). However, the weight of cerebella relative to body weight was significantly decreased in both female and male $\mathrm{KO}$ mice (Figs. S5i-k and 2c). We performed IF staining for PCs (using Calbindin, a specific marker for PCs [27-29]) on cerebellar sections of 2-month-old mice. The number of PCs in adult KO mice was significantly decreased compared to those of both WT mice and HT mice, while it did not differ between WT and HT mice (Fig. S51, m). The protein expression levels of NeuN (a neuronal marker) and Gephyrin (an inhibitory postsynaptic marker) were also substantially reduced in Synage KO cerebella compared to WT (Fig. S5n, o).

Cerebellar neurons are generated from two distinct neuroepithelial zones: the ventricular zone (VZ) and the more dorsally located rhombic lip (RL) [30, 31], while PCs are differentiated/generated from the VZ at E10.5-E12.5 [3234], before subsequently migrating dorsally to form a multicell-thick immature PC layer called the cerebellar plate at $\sim$ E14.5 [35]. We further sectioned cerebella sagittally and IF stained them for PCs [27-29] at six developmental stages (E12.5, E17.5, P4, P7, P14, and 2 months) [36]. The results showed that the VZ became thinner and revealed RL invagination in E12.5 Synage KO mice compared to the WT controls (Fig. 2d).

Given that the PCPs expand in concert with cerebellar development, and considering that several PC clusters (PCCs) are known to aggregate with the PCs forming a multilayer below the external germinal layer by E17.5 [37], it was informative when we observed obviously reduced numbers of PCPs and of PCCs in E17.5 Synage KO mice compared to the WT mice (Fig. 2e). During differentiation, mouse PCs are in cluster stage around E18 to P3 [38], and are in dispersal situation at P3-P7. Premature PCs arborize (maturation process) at $\mathrm{P} 12-\mathrm{P} 13$; the PCs maturation ends at around P18-P20 [39], and the cerebellum undergoes dramatic increases in size and changes after birth [40]. We found that the number of PCs was reduced in Synage KO mice at P4 (Fig. 2f), P7 (Fig. 2g), P14 (Fig. 2h), and 2 months (Fig. 2i).

In addition, we counted the numbers of major cerebellar neurons (PCs and GCs) and BGCs in the cerebellum at P10, $\mathrm{P} 23$, and 2 months, using Calbindin-positive cells to represent PCs, Gdf10-stained cells to determine BGCs [41-43], and the signal intensity of Hoechst 33342 staining in the GC layer to estimate GCs (since the signals for GCs-specific marker Pax6 had too much overlay with each other to accurately quantify). The numbers of PCs and GCs, but not BGCs, significantly decreased at P10 (Fig. S6a-d), P23 (Fig. S6a, e-g), and 2 months (Fig. S6a, h-j) in Synage KO 

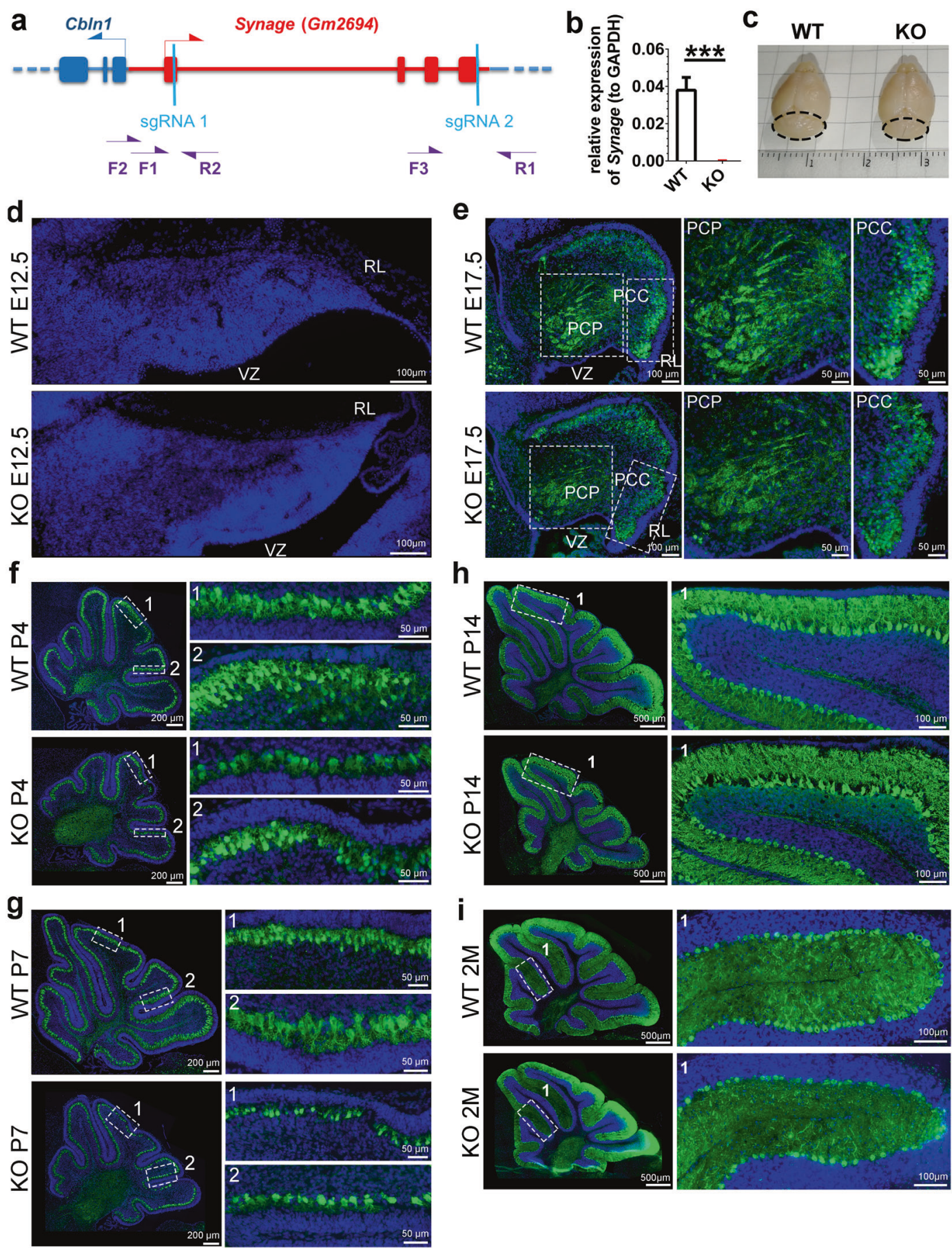

Fig. 2 Synage knockout mice show cerebellar defects and neuronal loss during cerebellar development. a Schematic representation of the position of Synage, Cbln1, sgRNAs, and genotyping primers (F forward primers, $\mathrm{R}$ reverse primers). b Relative expression levels of Synage in the cerebella of WT and knockout (KO) adult mice detected by RT-qPCR. c Gross morphology of representative brains from adult WT and KO male mice. d Hoechst 33342 staining of cerebella from

E12.5 WT and KO mice (WT, $n=9 ; \mathrm{KO}, n=6$ ). e-i Immunofluorescence staining of the Purkinje cell marker protein (Calbindin, green) in the cerebella from E17.5 (e), P4 (f), P7 (g), P14 (h), and 2month-old (i) WT and KO mice. WT (E17.5), $n=7$; $\mathrm{KO}$ (E17.5), $n=$ 3; WT (P4, P7, P14, and 2 months), $n=3$; KO (P4, P7, P14, and 2 months), $n=3$. Nuclei were stained with Hoechst 33342 (blue).

mice compared with WT mice. Overexpression of Synage in the cerebellum rescued the number of PCs to the level of WT mice at 3 weeks after injection by injecting AAV-EF1 $\alpha$ -
Synage into the cerebella of newborn Synage KO mice (Fig. 3a-c). These results supported that Synage is necessary for cerebellar development and maturation. 

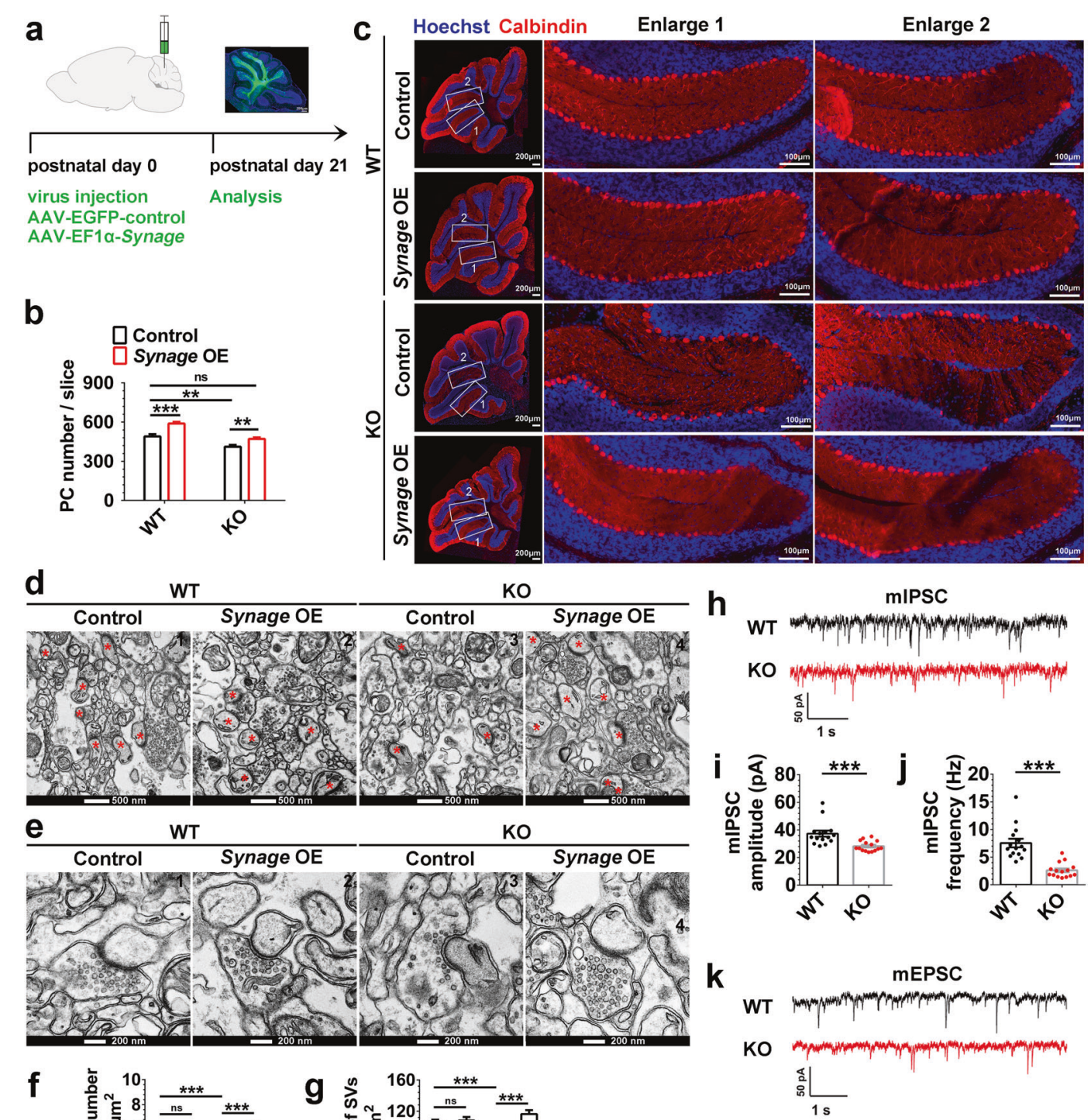
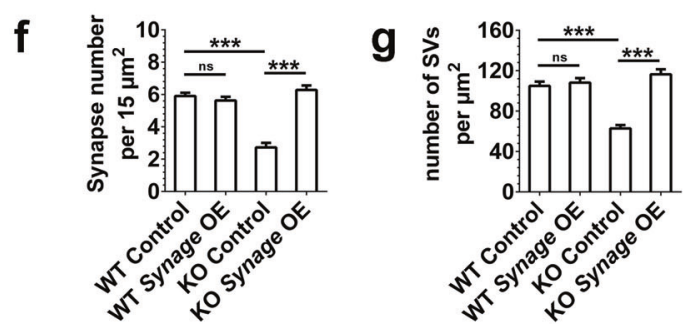

Fig. 3 Overexpression of Synage in the cerebella of knockout mice rescues the numbers of both Purkinje cells and synapses to the level of wild-type mouse. a Schematic representation of the AAV injection (AAV-EGFP-control and AAV-EF1 $\alpha$-Synage) and the analysis strategy for WT and KO mice. $\mathbf{b}, \mathbf{c}$ Quantification of the number of Purkinje cells (PCs) per cerebellar sections (b) and representative immunofluorescence staining images of PCs (labeled with Calbindin, red) (c) in 3-week-old WT and KO mouse cerebella after stereotaxic injection of AAV-EGFP-control (control) or AAV-EF1 $\alpha$-Synage (Synage OE) into the neonatal mouse cerebella. Nuclei were stained with Hoechst 33342 (blue). The numbers (1 and 2) show the enlarged areas. Left scale bar: $200 \mu \mathrm{m}$; scale bar of the enlarged regions: $100 \mu \mathrm{m}$ (WT Control, $n=7$; WT Synage OE, $n=8$; KO Control, $n=14$; KO Synage $\mathrm{OE}, \quad n=11)$. d-e Representative transmission electron microscopy (TEM) micrographs of synapses upon AVV-mediated
Synage overexpression (OE) on cerebellar cortex in adult WT and Synage KO mice. Synapses are indicated by red asterisks, upper scale bar: $500 \mathrm{~nm}(\mathbf{d})$, lower scale bar: $200 \mathrm{~nm}(\mathbf{e})$. f Quantification of the number of synapses per $15 \mu \mathrm{m}^{2}$ in three mice (WT Control, $n=93$; WT Synage OE, $n=47$; KO Control, $n=29$; KO Synage OE, $n=53$ ). g Quantification of the number of SVs per $\mu^{2}$ in WT and KO mice (WT Control, $n=191$; WT Synage OE, $n=84$; KO Control, $n=70$; KO Synage OE, $n=74$ ). $\mathbf{h}-\mathbf{j}$ Representative traces of mIPSCs from cerebellar PCs (h) and quantification of mIPSC amplitude (i) and frequency (j) in P26 WT and KO cerebella. Dots indicate data from individual experiments. $\mathbf{k}-\mathbf{m}$ Representative traces of mEPSCs from cerebellar PCs (k) and quantification of mEPSC amplitude (l) and frequency (m) in P26 WT and KO cerebella. Dots indicate data from individual experiments. 
Synage deletion leads to severe morphological and functional defects in synapses

Since synapses can form between neurons and are essential to neuronal function, the loss of neurons (PCs and GCs) upon Synage KO led us to investigate if there was also an ablation of cerebellar synapses after Synage KO. We performed TEM analyses on cerebellar cortex slides in adult WT and Synage KO mice to observe the numbers of synapses and synaptic vesicles (SVs). We found: (1) significantly reduced numbers of both synapses and SVs in presynaptic terminals in the cerebellar cortex of KO compared to WT mice (Fig. 3d-g). (2) Cerebella overexpressing Synage in adult WT mice showed no significant change in the number of synapses or SVs compared to WT mice (Fig. 3d-g). (3) Complementation of Synage expression in Synage KO mice rescued the numbers of both synapses and $\mathrm{SVs}$ (which reached the levels detected for WT mice) (Fig. 3d-g). The reduction in synapse density in Synage KO mice further suggests an additional deficit in synaptogenesis and/or in synapse maintenance. Moreover, the reduction in the number of SVs also shows a deficit in the structure and function of individual synapses.

The severe morphological defects in the cerebellar synapses of Synage KO mice suggested that synaptic connectivity and function are potentially adversely affected. We thus evaluated the excitatory and inhibitory synapses of PCs by measuring mIPSCs and mEPSCs from PCs on cerebellar sagittal slices using a whole-cell patch-clamp. Both amplitude and frequency of mIPSCs were reduced in Synage KO mice (Fig. 3h-j), as were mEPSCs (Fig. 3k-m). These results indicate that synaptic connectivity and function in PCs in the cerebella of Synage KO mice are severely compromised.

Aberrant cerebellar morphology often leads to motor behavior defects [44]. The rotarod test and the balance beam test, well-established methods to evaluate motor coordination in rodents [23, 45], showed that motor abilities and motor-dependent learning and memory were severely impaired in Synage KO mice (Fig. S7a, b). Taken together, our findings of the decrease in cerebellar neurons and synapses and the defects in neuronal synaptic function in Synage KO mice all strongly suggest that the severe morphological and functional defects in neurons and synapses are responsible for the observed motor dysfunction of Synage KO mice.

\section{Synage IncRNA maintains stability and function of cerebellar synapses partially by regulating Cbln 1 mRNA}

$C b \ln 1$, a cerebellum highly expressed and synapse-related glycoprotein-coding gene, is upstream of Synage and is transcribed in the opposite direction (Fig. S2a). CBLN1 protein is secreted from cerebellar GCs to act as a critical synapse organizer between PFs and PCs [6, 7]. Since many lncRNAs regulate their neighboring protein-coding genes, we asked whether Synage lncRNA also modulates $C b \ln 1$ expression. C8-D1A cells have poor transfection efficiency, which prevented us from performing in vitro experiments in this cell line. After screening for many cell lines, we found that two isoforms of Synage (n285242, n264625) were robustly expressed in the HT-22 cell line (Fig. S8a), which is a mouse hippocampal neuronal cell line that has higher transfection efficiency than the C8-D1A cell line [46, 47]. Therefore, we designed two shRNAs specifically targeting Synage, and transfected them into the HT-22 cell line to knockdown Synage (Fig. S8b). The results indicated that the expression levels of both Cbln1 mRNA and protein were significantly reduced upon Synage knockdown in the HT-22 cell line (Fig. S8b-d).

To further test the effect of Synage knockdown on CblnI in vivo, we injected the Synage shRNAs into the cerebella of adult WT mice. Two weeks later, we again observed that Cbln1 expression was diminished in the cerebellum compared with its expression in the olfactory bulb (Fig. S8e), Cbln1 mRNA and protein levels had a similar decrease in Synage KO mouse cerebellum (Figs. 4a and S8f, g). We also found that overexpression of Synage in its KO mouse significantly increased the CBLN1 expression compared with KO control group (Figs. 4b and S8h). Thus, both in vivo and in vitro Synage knockdown as well as in vivo Synage KO experiments demonstrated that Synage regulates the expression of Cbln1. Given the important role of $C b \ln 1$ in the regulation of cerebellar synaptic function, these results suggest that the Synage lncRNA may be also involved in regulating cerebellar synaptic functions.

Given their spatial proximity in the genome, we asked whether Synage KO inhibiting Cbln1 expression is due to inadvertent excision of some potential regulatory elements upstream of the $C b \ln 1$ gene. We thus performed a nuclear run on assay [48-50] on WT and KO mice cerebella, and found that Synage deletion did not affect the number of nascent $C b \ln 1$ transcripts (Fig. 4c), although the total $C b \ln 1$ mRNA and protein levels were significantly decreased in the cerebella of 2-month-old Synage KO mice (Figs. 4a and S8f, g). These data suggest that Synage regulates $C b \ln 1$ expression at the mRNA and/or protein levels.

Synage deletion exerted a strong influence on both the mRNA and protein levels of Cbln1; however, we did not detect the CBLN1 protein in our in vivo RNA pulldown-MS experiment as a potential Synage-associating protein. Considering our finding that Synage is localized in the cytoplasm of cerebellar cells, we explored the possibility that Synage may function as a ceRNA by competing with miRNAs [51, 52]. Specifically, we predicted the shared 


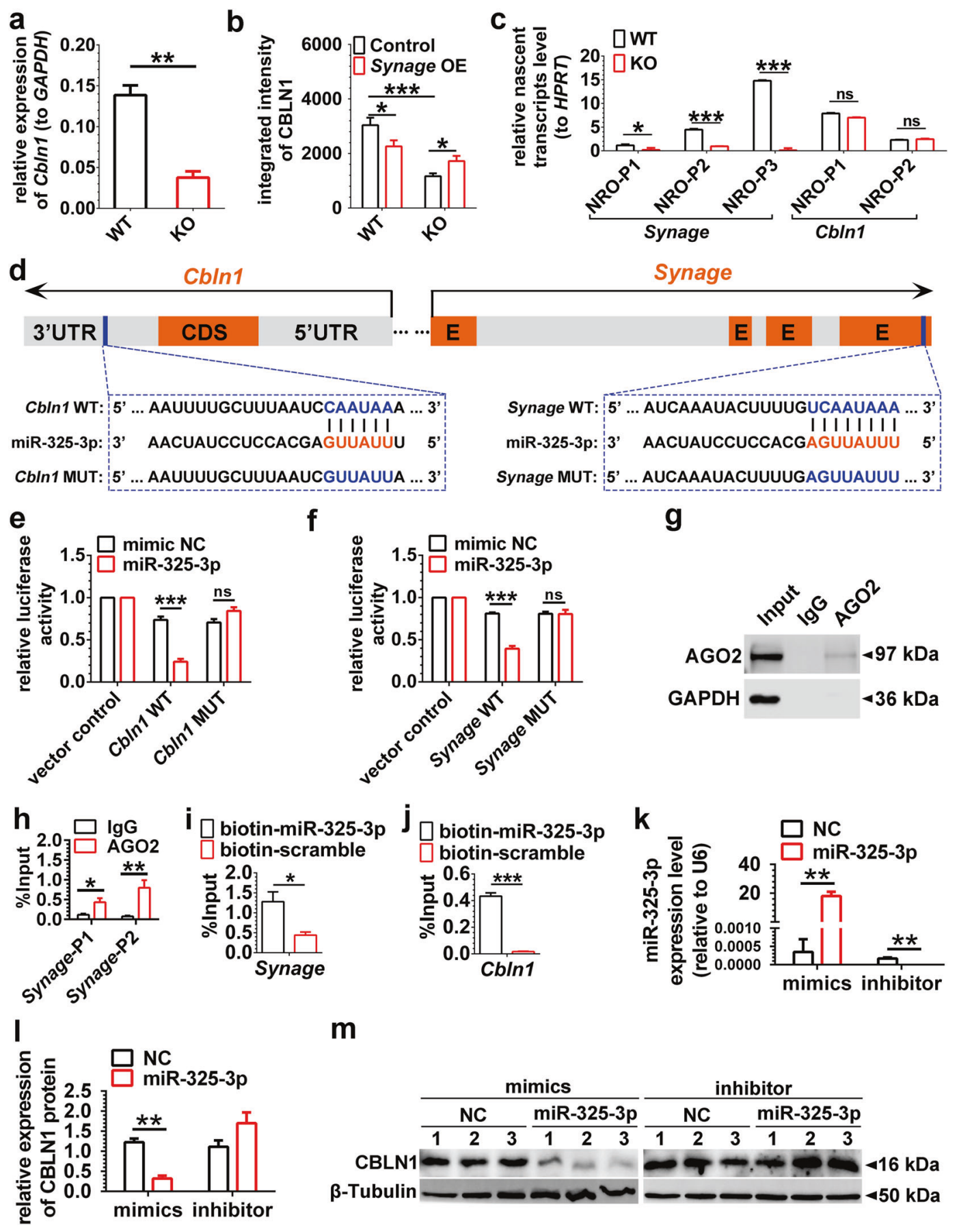

miRNA targets for Cbln1 and Synage using the miRNAtarget (mRNA/lncRNA) interaction modules of both StarBase v3 [53, 54] and DIANA-LncBase v2 [55], which identified a perfectly conserved seed match, mmu-miR-325$3 \mathrm{p}$, in the $3^{\prime} \mathrm{UTR}$ region of Cbln1 and the last exon of two isoforms of Synage (n285242, n264625) (Fig. 4d).

To confirm the prediction for their targeting relationship, we constructed mutant $C b \ln 1-3^{\prime}$ UTR and mutant Synage luciferase reporter plasmids, which retained the appropriate AT composition (Fig. 4d). The n285242 is one of the
Synage isoforms and its full length was used in this experiment. HT-22 cells were then co-transfected with the NC or mmu-miR-325-3p and WT Cbln1-3'UTR or mutant Cbln1-3'UTR, as well as WT Synage or mutant Synage luciferase reporter gene plasmids. Dual luciferase reporter assay results showed that mmu-miR-325-3p significantly reduced the luciferase activities from both the WT $C b \ln 1$ and WT Synage luciferase reporter gene plasmids; no reductions were observed with the mutant $C b \ln 1$ or mutant Synage luciferase reporter gene plasmids (Fig. 4e, f). These 
Fig. 4 Synage IncRNA regulates $C b \ln 1$ mRNA through the AGO2miR-325-3p pathway. a Relative expression level of $C b \ln 1$ mRNA in adult WT and KO mouse cerebella. b Relative quantification of integrated intensity of CBLN1 protein in the cerebellar cortex of 3-weekold WT and KO mice detected by immunofluorescence staining after stereotaxic injection of AAV-control or AAV-Synage (Synage OE) into the neonatal mouse cerebellum. c Relative nascent transcript levels of both Synage and Cbln1 using multiple pairs of primers, normalized to housekeeping gene HPRT (hypoxanthine guanine phosphoribosyl transferase). NRO nuclear run on, P primer pairs. d Schematic representation of the predicted binding sites of miR-325-3p on Synage and Cbln1 (CDS coding sequence, UTR untranslated region, E exon). e Relative luciferase activity of vector control and WT Cbln1-3'UTR and mutant Cbln1-3'UTR luciferase reporter gene plasmids upon co-transfection of mimic negative control (NC) or miR$325-3 p$ in the HT-22 cell line. f Relative luciferase activity of vector control and WT Synage and mutant Synage luciferase reporter gene plasmids upon co-transfection of mimic NC or miR-325-3p in the HT22 cell line. Data are presented as the relative ratio of firefly luciferase activity to Renilla luciferase activity. $\mathbf{g}$ Western blot analysis of AGO2 protein immunoprecipitation by $\mathrm{AGO} 2$ antibody in AGO2-RNA immunoprecipitation. $\mathbf{h}$ The amount of Synage lncRNA binding to AGO2 or IgG was quantified as a percentage of input in IP by RTqPCR (Synage-P1, a primer pair specifically targeting n264625; Synage-P2, a primer pair targeting both $\mathrm{n} 264625$ and $\mathrm{n} 285242)$. i, j The amount of Synage lncRNA (i) and Cbln1 mRNA (j) binding to miR-325-3p was quantified as a percentage of input in miR-325-3p pull-down assays by RT-qPCR. k-m Relative expression levels of miR-325-3p with in vitro transfection of miR-325-3p mimics and inhibitor in the HT-22 cell line, normalized to U6 (k). Quantification (l) and representative images of Western blots (m) for CBLN1 with in vitro transfection of miR-325-3p mimics and inhibitor in the HT-22 cell line.

results together indicated that mmu-miR-325-3p directly binds to the $3^{\prime} \mathrm{UTR}$ of $C b \ln 1 \mathrm{mRNA}$ and to the last exon of Synage.

MicroRNAs silence gene expression by repressing translation and promoting target mRNA degradation [56]. To determine whether Synage regulates $C b \ln 1$ as a ceRNA by competing for the above identified shared miRNA (mmu-miR-325-3p) in the AGO2-miRNA pathway, we made use of the published AGO2 CLIP-Seq data from mouse cortex tissue (GSE73058) to identify AGO2-bound RNAs [57]. We found that AGO2 had multiple binding sites located in the Cbln1 and Synage (Supplementary Table S1). We performed an AGO2-RIP-qPCR experiment using mouse cerebellum tissue, which showed that n285242 and n264625 (two isoforms of Synage) were pulled down in the AGO2 complex (Fig. 4g, h). Conversely, a biotin-labeled mmu-miR-325-3p RNA was able to pull-down both Synage (by a primer pair that targeting all of the three isoforms) and Cbln1 transcripts (Fig. 4i, j). We next determined the effects of mmu-miR-325-3p on Synage and Cbln1 expression, by detecting the respective decrease or increase in CBLN1 protein in response to the mmu-miR-325-3p mimics or inhibitor in the transfected HT-22 cell line (Fig. 4k-m). Together, our data indicate that Synage (particularly, isoforms of $\mathrm{n} 285242$ and $\mathrm{n} 264625)$ acts as a sponge for mmu-miR-325-3p to regulate $C b \ln 1$ mRNA expression, which leads to the change of the CBLN1 protein levels.

Cbln1 $1^{-1-}$ mice showed cerebellar ataxia and impaired performance accompanied by a significant reduction in the number of PF-PC synapses, as well as severe impairment to synaptic function (Supplementary Table S2) [6, 58-62]. Synage KO mice exhibited phenotypes consistent with these reports, including synapse reduction and dysfunction, as well as motor defects, but otherwise showed more severe impairment than the phenotypes of $C b \ln 1^{-l-}$ mice, including decreased SVs, obvious neuronal loss, decreased cerebellar weight, and reduced fertility (Supplementary Table S2). On the other hand, Cbln1 heterozygotes showed more than half of CBLN1 protein loss in the cerebellum but displayed no markedly impaired performance on the accelerating rotarod test [6]. CbInl heterozygous mice might have developed some compensatory mechanisms, while Synage KO- or knockdown-induced 50\% Cbln1 downregulation may be sufficient to manifest the phenotype of synapses loss. In addition, Cbln1 was also found to mediate specific aspects of fear conditioning and spatial memory differentially and regulate both motor and nonmotor functions [63]. We thus speculated that both Synage and $C b \ln 1$ likely have additional functions that are independent of one another. Synage probably modulates cerebellar development and function through other mechanisms in addition to regulation of $C b \ln 1$ expression.

\section{Synage IncRNA modulates cerebellar synapses by orchestrating assembly of synaptic LRP1-HSP90AA1- PSD-95 complex}

In our in vivo RNA pull-down-MS experiments, LRP1 and HSP90AA1 were the two strongest candidates identified by MS in the cerebellum (Fig. 5a, b). We conducted LRP1-RIP and HSP90AA1-RIP assays (Fig. 5c, d), and Synage was detected in both LRP1-RIP and HSP90AA1-RIP samples (Fig. 5e, f), confirming that Synage bound both LRP1 and HSP90AA1 and might form a complex. LRP1 is known to interact with PSD-95, through which it modulates synaptic function $[9,64]$. We noted a similarity of the neuronal loss in mice induced by LRP1 deletion and the Synage KO (Supplementary Table S2). We thus speculated that PSD-95 may also be in the complex of LRP1-HSP90AA1-Synage. RNAFISH in combination with IF using different fluorophores to label Synage, LRP1, PSD-95, and HSP90AA1, showed colocalization of Synage with all three proteins in PCs of WT cerebella, and the co-localization was significantly reduced in PCs of Synage KO cerebella (Fig. 5g, h).

We also examined the influence of Synage on LRP1HSP90AA1-PSD-95 interactions by performing co-IP with mouse cerebellum tissue (Fig. 5i-k) and found that the 


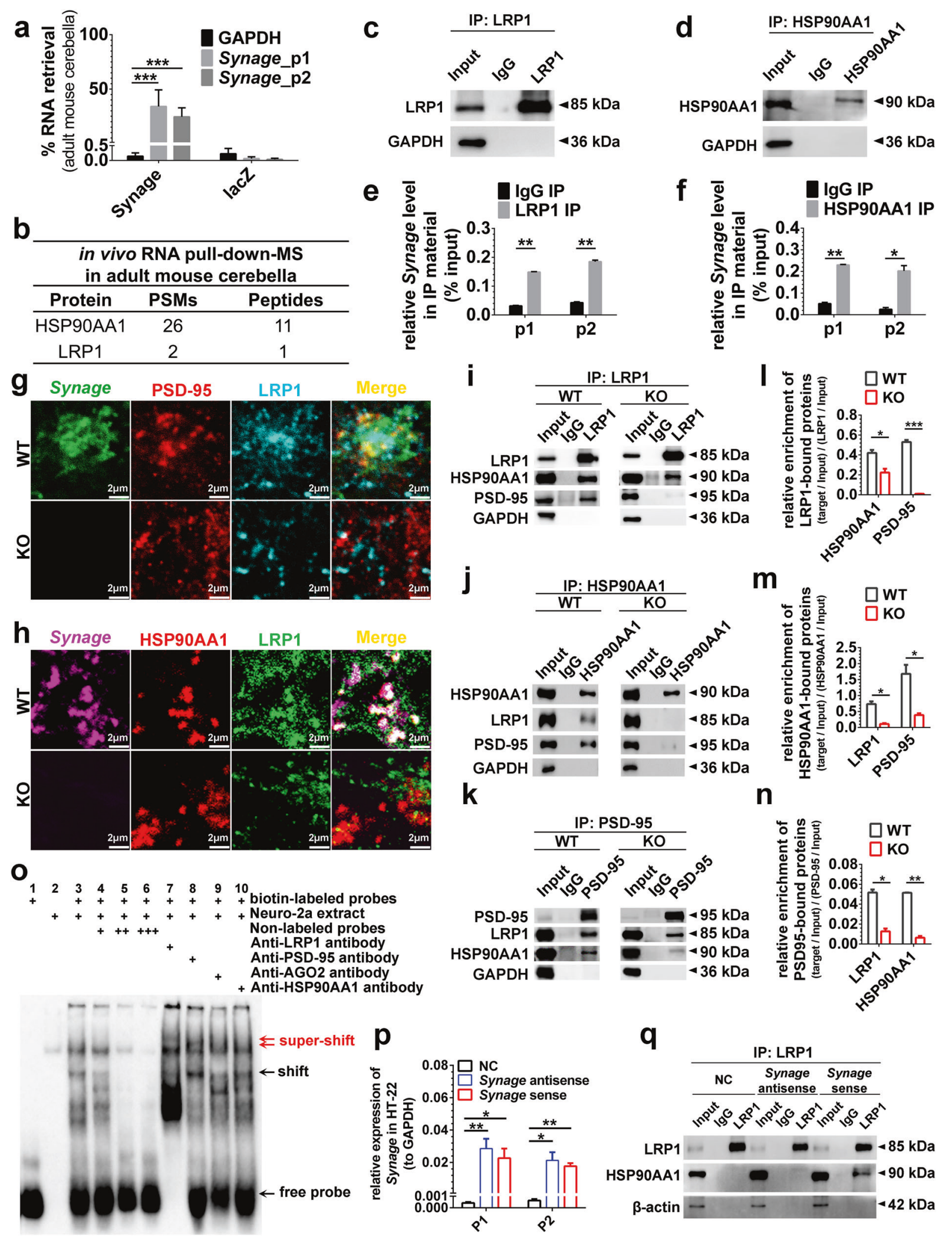

interactions among all three of these proteins were reduced in Synage KO mice compared with WT controls (Fig. 51-n). Although IF experiments revealed a decrease in the protein level of LRP1 in the cerebellar cortex of KO mice compared to WT mice (Figs. 5g, h and S9a), the total protein levels of the LRP1, HSP90AA1, and PSD-95 did not differ when 
Fig. 5 Synage IncRNA acts as an organizer to scaffold the synaptic LRP1-HSP90AA1-PSD-95 complex. a RT-qPCR analysis of in vivo RNA pull-down showing retrieval of Synage lncRNA with Synagespecific probes in the adult mouse cerebella. LacZ probes were the negative controls. Synage_p1 and Synage_p2 represent different primers targeting Synage (all three isoforms). b List of top Synagebinding proteins detected in the adult mouse cerebella by in vivo RNA pull-down-mass spectrometry. c-f Western blots assessing LRP1 and HSP90AA1 immunoprecipitation (IP) by anti-LRP1 (c) or antiHSP90AA1 (d) antibody in RNA immunoprecipitation (RIP). Relative enrichment of Synage binding to LRP1 (e) or HSP90AA1 (f) or IgG in IP was quantified as a percentage of input by RT-qPCR. p1 and p2 represent different primers targeting Synage (all three isoforms). $\mathbf{g}$, h Co-localization analysis of Synage with PSD-95 and LRP1 (g) as well as with HSP90AA1 and LRP1 (h) by RNA-FISH of Synage and immunofluorescence staining of these proteins in the 2-month-old WT and KO mouse cerebella. $\mathbf{i}-\mathbf{n}$ Western blots and relative quantification of the interactions among LRP1 (i, l), HSP90AA1 (j, m), and PSD-95 $(\mathbf{k}, \mathbf{n})$ as determined by co-IP analysis in the adult WT and KO mouse cerebella. o RNA-electrophoretic mobility shift assays (EMSAs) for verification of the direct interactions between Synage and its binding proteins in the Neuro-2a cell line. p, q RT-qPCR analysis of the overexpression level of Synage (sense) in the HT-22 cell line (p), Western blots assessing LRP1 and HSP90AA1 coimmunoprecipitation by anti-LRP1 antibody after Synage overexpression in the HT-22 cell line, Synage antisense RNA was used as a negative control $(\mathbf{q})$.

examined by Western blots of cerebella samples of adult WT versus Synage KO mice (Fig. S9b, c). These data suggest that Synage functions in synapse stability not by reducing protein levels per se, but rather by somehow regulating Synage-dependent assembly of the LRP1HSP90AA1-PSD-95 complex in the cerebellar cortex.

We further investigated the possibility of interactions between Synage and each of these proteins (LRP1, PSD-95, and HSP90AA1) using biotin-labeled n424059 (one of the Synage isoforms) sense probes in the Neuro-2a cell line by EMSAs (Fig. 5o). The Neuro-2a cell line is a fast-growing mouse neuroblastoma cell line $[65,66]$, and n424059 is not expressed in this cell line, so that we could exclude the interference from endogenous n424059 (Fig. S10). The EMSAs data revealed that LRP1 and PSD-95 could each bind to Synage (Fig. 5o). Furthermore, overexpression of Synage in the HT-22 cell line significantly increased the interaction between LRP1 and HSP90AA1 compared with the controls, as shown by RT-qPCR and co-IP experiments (Fig. 5p, q).

In addition, we knocked down each protein (LRP1, HSP90AA1, and PSD-95) by three shRNAs specifically targeting their mRNAs respectively in the HT-22 cell line (Fig. S11a-c). PSD-95 protein was dramatically reduced upon knockdown of LRP1 or HSP90AA1 in the HT-22 cell line (Fig. S11a, b, d, e). Furthermore, the LRP1 protein was significantly upregulated upon knockdown of HSP90AA1 or PSD-95 (Fig. S11b, c, e, f). These results demonstrated that knocking down LRP1 or HSP90AA1 or PSD-95 impacted the levels of the other two proteins comprising the
LRP1-HSP90AA1-PSD-95 complex. We also found that, after LRP1 knockdown, overexpression of Synage in the HT-22 cell line significantly increased the extent of the LRP1-HSP90AA1 interaction as compared to the random shRNA control (Fig. S11g, h), indicating that LRP1 depletion inhibits the interactions between LRP1-HSP90AA1 and Synage. Together, these results demonstrate the function of Synage as a key organizer of the LRP1-HSP90AA1-PSD-95 complex in PCs, to maintain the stability and function of these proteins in cerebellar synapses.

\section{Discussion}

IncRNAs are abundant in the brain. In the present work, we discovered that a cerebellum highly expressed lncRNA, Synage, mainly distributed in the cytoplasm and extending into neurites and synapses, regulate cerebellar synaptic stability and cerebellar development starting at the E12.5 embryo stage. Synage KO leads to a dramatic decrease in cerebellar neuron number, synapse density, and synaptic stability in mice cerebella. At the molecular level, we showed that Synage regulates synaptic stability and function by Synage-dependent assembly of the LRP1-HSP90AA1PSD-95 complex in the cerebellar cortex (Fig. 6). Both HSP90AA1 and LRP1 have been reported to exhibit antiapoptotic effects in neurons by directly binding and/or activating Akt kinase [67, 68]. We thus speculate that the interaction of Synage with HSP90AA1 and LRP1 might increase Akt activation and thus protect PC and GC neurons from apoptosis in the WT mice. In addition, Synage appears to be multitasking in that it also functions as a ceRNA to adsorb a Cbln1-targeted miRNA to upregulate $C b \ln 1$ expression in GCs (Fig. 6). Synage KO mice were more severely impaired than the $C b \ln 1^{-1-}$ mice (Supplementary Table S2), consistent with our data showing that Synage exerts its function via at least two mechanisms, first by regulating the expression level of $C b \ln 1$ (in GCs), and second by orchestrating the formation of the synaptic LRP1-HSP90AA1-PSD-95 complex (in PCs).

The synapses between climbing fibers and PCs, as well as those between PFs and PCs, are known to form in the cerebellar cortex after birth [69-71]. Our data, however, showed that the loss of PCs occurred during embryonic development of the Synage KO cerebellum. Accordingly, our data support that the observed decrease in PCs number in the Synage KO mice during embryonic development clearly has longer term impacts that manifest later as reductions in synapse density and in synaptic activity after birth. Although we cannot rule out the possibility that the reduced PCs number may also affect synaptic formation or maintenance, our data indicate that altered synaptic formation (or maintenance) after birth is impacted by the 

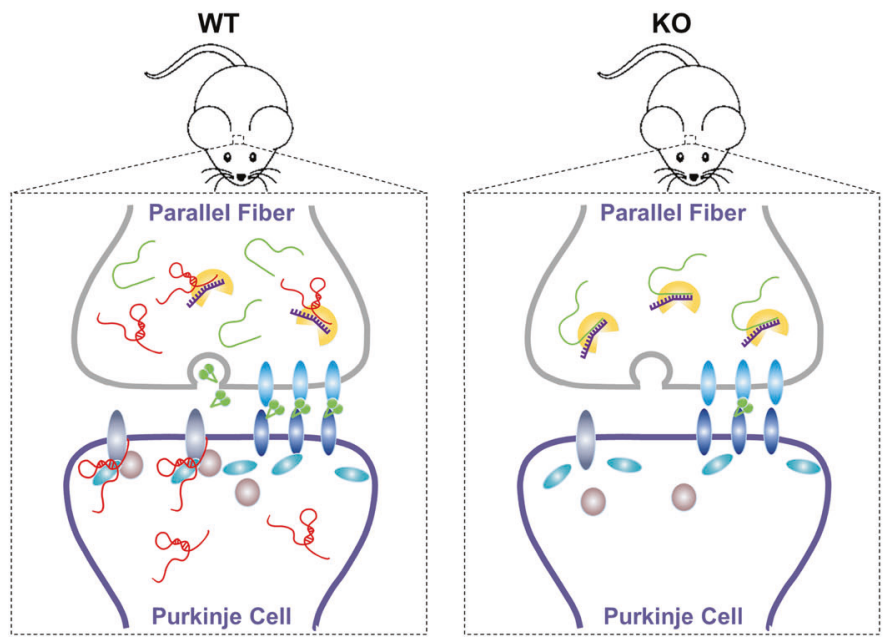

e Synage IncRNA

LRP1 protein

PSD-95 protein

HSP90AA1 protein

NEUREXIN protein

- GluRס2 protein

\& CBLN1 protein

ᄃ Cblnt mRNA

- mmu-miR-325-3p-RISC complex
Fig. 6 A schematic diagram of the mechanism of the Synage IncRNA in the regulation of synaptic and neuronal function in the WT and Synage KO mouse cerebella. Synage lncRNA regulates stability and function of cerebellar synapses via at least two mechanisms. One is through the function of Synage as a sponge for mmu-miR-
$325-3 p$ to regulate $C b \ln 1$ mRNA expression, which leads to the change of the CBLN1 protein levels. The other function is to serve as a scaffold for orchestrating the assembly of synaptic LRP1-HSP90AA1PSD-95 complex. destruction of Synage-binding protein complexes in the Synage KO cerebellum.

In summary, this study demonstrates that cerebellum highly expressed Synage IncRNA regulates the formation of the LRP1-HSP90AA1-PSD-95 complex in PCs and Cbln1 expression in GCs. These interacting components are located in synapses where they perform unique roles, thereby differentially affecting synaptic stability and functionality, which in turn affects the growth of neurons, the development and function of the cerebellum, and greatly contributes to motor function during development. Since the genomic localization and the cerebellar distribution of Synage are conserved from mice to humans, targeting of the LRP1HSP90AA1-PSD-95-Synage complex or Synage-Cbln1 interactions may protect against developmental defects in humans and in model organisms; insights into their neuroprotective mechanisms can potentially yield pharmaceuticals designed to extend neurological health and synaptic function, and to mitigate cerebellar neurodevelopmental disorders.

\section{Data availability}

The accession number for the ribo-minus RNA-Seq data reported in this paper is CRA001819 and is publicly accessible at https://bigd.big.ac.cn/gsa.

Acknowledgements We thank Dr Wei Xiong (USTC) for providing the mouse brain stereotactic injection instrument and the experimental platform for feeding and behavior tests of KO mice and for helpful suggestions. We thank Dr Jiangning Zhou (USTC), Dr Aihui Tang (USTC), and Dr Shouhong Guang (USTC) for constructive suggestions. We also appreciate Dr Jiangning Zhou (USTC) for providing the balance beam instrument and Neuro-2a and HT-22 cell lines. We thank
Dr Yong Shen (USTC) for providing antibodies for Western blots (anti-NeuN, -Gephyrin and -PSD-95 antibodies). We thank Dr Xiangting Wang (USTC) for providing the C8-D1A cell line and for constructive suggestions. We also appreciate Chunying Yin (USTC) for TEM technical support.

Author contributions XS supervised the project; XS and FW conceived and designed the study; young and old brain samples for rmRNA-Seq were provided and collected by SM and JS; FW performed bioinformatic analyses with the help of RW, discovered Synage lncRNA. and predicted its function in vitro and in vivo; FW and QW carried out phenotype analyses, section staining, and behavior tests; FW and BL performed the molecular mechanism experiments; SW and YZ performed mass spectrometry detection. LM and FW conducted the electrophysiological experiment with supervision from $\mathrm{ZZ}$; YZ and ZX worked collaboratively with XS to supervise the project; $\mathrm{CN}$ provided human cerebellum sample; $\mathrm{FW}$ analyzed the data and produced the figures; FW and XS wrote the paper. QW and BL edited the manuscript. All authors reviewed the manuscript and approve of its contents.

Funding This work was funded by the National Natural Science Foundation of China (91540107 to XS) and the State Key Laboratory of Neuroscience, Shanghai Institutes for Biological Sciences, Chinese Academy of Sciences (SKLN-201805 to XS), the Natural Science Foundation of Anhui Province (2008085QC160 to FW), and the Science and Technology Project grant from Anhui Province (1604a0802069 to $\mathrm{CN})$.

\section{Compliance with ethical standards}

Conflict of interest The authors declare no competing interests.

Ethics approval All animal experiments were carried out in accordance with the guidelines of and approved by the University of Science and Technology of China (USTC) Animal Resources Center and University Animal Care and Use Committee (permit number: USTCACUC1801015). 
Publisher's note Springer Nature remains neutral with regard to jurisdictional claims in published maps and institutional affiliations.

Open Access This article is licensed under a Creative Commons Attribution 4.0 International License, which permits use, sharing, adaptation, distribution and reproduction in any medium or format, as long as you give appropriate credit to the original author(s) and the source, provide a link to the Creative Commons license, and indicate if changes were made. The images or other third party material in this article are included in the article's Creative Commons license, unless indicated otherwise in a credit line to the material. If material is not included in the article's Creative Commons license and your intended use is not permitted by statutory regulation or exceeds the permitted use, you will need to obtain permission directly from the copyright holder. To view a copy of this license, visit http://creativecommons. org/licenses/by/4.0/.

\section{References}

1. Sathyanesan A, Zhou J, Scafidi J, Heck DH, Sillitoe RV, Gallo V. Emerging connections between cerebellar development, behaviour and complex brain disorders. Nat Rev Neurosci. 2019;20: 298-313.

2. Manto M, De Zeeuw CI. Diversity and complexity of roles of granule cells in the cerebellar cortex. Editor Cerebellum. 2012;11:1-4

3. Marzban H, Del Bigio MR, Alizadeh J, Ghavami S, Zachariah RM, Rastegar M. Cellular commitment in the developing cerebellum. Front Cell Neurosci. 2014;8:450.

4. Ito M. Historical review of the significance of the cerebellum and the role of Purkinje cells in motor learning. Ann N Y Acad Sci. 2002;978:273-88.

5. Heiney SA, Kim J, Augustine GJ, Medina JF. Precise control of movement kinematics by optogenetic inhibition of Purkinje cell activity. J Neurosci. 2014;34:2321.

6. Hirai H, Pang Z, Bao D, Miyazaki T, Li L, Miura E, et al. Cbln1 is essential for synaptic integrity and plasticity in the cerebellum. Nat Neurosci. 2005;8:1534-41.

7. Ito-Ishida A, Okabe S, Yuzaki M. The role of Cbln1 on Purkinje cell synapse formation. Neurosci Res. 2014;83:64-8.

8. Eugenin EA, King JE, Nath A, Calderon TM, Zukin RS, Bennett $\mathrm{MV}$, et al. HIV-tat induces formation of an LRP-PSD-95NMDAR-nNOS complex that promotes apoptosis in neurons and astrocytes. Proc Natl Acad Sci USA. 2007;104:3438-43.

9. Maier W, Bednorz M, Meister S, Roebroek A, Weggen S, Schmitt $\mathrm{U}$, et al. LRP1 is critical for the surface distribution and internalization of the NR2B NMDA receptor subtype. Mol Neurodegener. 2013;8:25.

10. May P, Rohlmann A, Bock HH, Zurhove K, Marth JD, Schomburg ED, et al. Neuronal LRP1 functionally associates with postsynaptic proteins and is required for normal motor function in mice. Mol Cell Biol. 2004;24:8872-83.

11. Liu Q, Trotter J, Zhang J, Peters MM, Cheng H, Bao J, et al. Neuronal LRP1 knockout in adult mice leads to impaired brain lipid metabolism and progressive, age-dependent synapse loss and neurodegeneration. J Neurosci. 2010;30:17068-78.

12. Mantuano E, Lam MS, Shibayama M, Campana WM, Gonias SL. The NMDA receptor functions independently and as an LRP1 coreceptor to promote Schwann cell survival and migration. J Cell Sci. 2015;128:3478-88.

13. Goff LA, Groff AF, Sauvageau M, Trayes-Gibson Z, SanchezGomez DB, Morse M, et al. Spatiotemporal expression and transcriptional perturbations by long noncoding RNAs in the mouse brain. Proc Natl Acad Sci USA. 2015;112:6855-62.
14. Bond AM, VanGompel MJW, Sametsky EA, Clark MF, Savage JC, Disterhoft JF, et al. Balanced gene regulation by an embryonic brain non-coding RNA is critical for GABA circuitry in adult hippocampus. Nat Neurosci. 2009;12:1020-7.

15. Ramos AD, Andersen RE, Liu SJ, Nowakowski TJ, Hong SJ, Gertz C, et al. The long noncoding RNA Pnky regulates neuronal differentiation of embryonic and postnatal neural stem cells. Cell Stem Cell. 2015;16:439-47.

16. Raveendra BL, Swarnkar S, Avchalumov Y, Liu X-A, Grinman E, Badal K, et al. Long noncoding RNA GM12371 acts as a transcriptional regulator of synapse function. Proc Natl Acad Sci. 2018;115:E10197.

17. Mercer TR, Dinger ME, Sunkin SM, Mehler MF, Mattick JS. Specific expression of long noncoding RNAs in the mouse brain. Proc Natl Acad Sci USA. 2008;105:716-21.

18. Guttman M, Donaghey J, Carey BW, Garber M, Grenier JK, Munson G, et al. lincRNAs act in the circuitry controlling pluripotency and differentiation. Nature. 2011;477:295-300.

19. Li YP, Duan FF, Zhao YT, Gu KL, Liao LQ, Su HB, et al. A TRIM71 binding long noncoding RNA Trincr1 represses FGF/ERK signaling in embryonic stem cells. Nat Commun. 2019;10:1368.

20. Mahmood T, Yang PC. Western blot: technique, theory, and trouble shooting. N Am J Med Sci. 2012;4:429-34.

21. Chu C, Zhang QC, da Rocha ST, Flynn RA, Bharadwaj M, Calabrese JM, et al. Systematic discovery of Xist RNA binding proteins. Cell. 2015;161:404-16.

22. Lal A, Thomas MP, Altschuler G, Navarro F, O’Day E, Li XL, et al. Capture of microRNA-bound mRNAs identifies the tumor suppressor miR-34a as a regulator of growth factor signaling. PLoS Genet. 2011;7:e1002363.

23. Luong TN, Carlisle HJ, Southwell A, Patterson PH. Assessment of motor balance and coordination in mice using the balance beam. J Vis Exp: JoVE. 2011;49:2376.

24. Alliot F, Pessac B. Astrocytic cell clones derived from established cultures of 8-day postnatal mouse cerebella. Brain Res. 1984;306: 283-91.

25. Liu S, Wang Z, Chen D, Zhang B, Tian RR, Wu J, et al. Annotation and cluster analysis of spatiotemporal- and sex-related lncRNA expression in rhesus macaque brain. Genome Res. 2017;27:1608-20

26. Zhang XQ, Wang ZL, Poon MW, Yang JH. Spatial-temporal transcriptional dynamics of long non-coding RNAs in human brain. Hum Mol Genet. 2017;26:3202-11.

27. Ito-Ishida A, Kakegawa W, Kohda K, Miura E, Okabe S, Yuzaki M. Cbln1 downregulates the formation and function of inhibitory synapses in mouse cerebellar Purkinje cells. Eur J Neurosci. 2014;39:1268-80.

28. Zhang B, Chen LY, Liu X, Maxeiner S, Lee SJ, Gokce O, et al. Neuroligins sculpt cerebellar Purkinje-cell circuits by differential control of distinct classes of synapses. Neuron. 2015;87:781-96.

29. Sergaki MC, Ibanez CF. GFRalpha1 regulates purkinje cell migration by counteracting NCAM function. Cell Rep. 2017;18:367-79.

30. Hatten ME, Alder J, Zimmerman K, Heintz N. Genes involved in cerebellar cell specification and differentiation. Curr Opin Neurobiol. 1997;7:40-7.

31. Yamada M, Seto $\mathrm{Y}$, Taya S, Owa T, Inoue $\mathrm{YU}$, Inoue $\mathrm{T}$, et al. Specification of spatial identities of cerebellar neuron progenitors by ptf1a and atoh1 for proper production of GABAergic and glutamatergic neurons. J Neurosci. 2014;34:4786-800.

32. Minaki $Y$, Nakatani T, Mizuhara E, Inoue T, Ono Y. Identification of a novel transcriptional corepressor, Corl2, as a cerebellar Purkinje cell-selective marker. Gene Expr Patterns. 2008;8:418-23.

33. Hashimoto M, Mikoshiba K. Neuronal birthdate-specific gene transfer with adenoviral vectors. J Neurosci. 2004;24:286-96. 
34. Hashimoto M, Mikoshiba K. Mediolateral compartmentalization of the cerebellum is determined on the "birth date" of Purkinje cells. J Neurosci. 2003;23:11342-51.

35. Miyata T, Ono Y, Okamoto M, Masaoka M, Sakakibara A, Kawaguchi A, et al. Migration, early axonogenesis, and Reelindependent layer-forming behavior of early/posterior-born Purkinje cells in the developing mouse lateral cerebellum. Neural Dev. 2010;5:23.

36. Yuasa S, Kawamura K, Ono K, Yamakuni T, Takahashi Y. Development and migration of Purkinje cells in the mouse cerebellar primordium. Anat Embryol. 1991;184:195-212.

37. Fujita H, Morita N, Furuichi T, Sugihara I. Clustered fine compartmentalization of the mouse embryonic cerebellar cortex and its rearrangement into the postnatal striped configuration. J Neurosci. 2012;32:15688-703.

38. Rahimi-Balaei M, Bergen H, Kong J, Marzban H. Neuronal migration during development of the cerebellum. Front Cell Neurosci. 2018;12:484.

39. Wang VY, Zoghbi HY. Genetic regulation of cerebellar development. Nat Rev Neurosci. 2001;2:484-91.

40. Goldowitz D, Hamre K. The cells and molecules that make a cerebellum. Trends Neurosci. 1998;21:375-82.

41. Mecklenburg N, Martinez-Lopez JE, Moreno-Bravo JA, Perez-Balaguer A, Puelles E, Martinez S. Growth and differentiation factor 10 (Gdf10) is involved in Bergmann glial cell development under Shh regulation. Glia. 2014;62:1713-23.

42. Koirala S, Corfas G. Identification of novel glial genes by singlecell transcriptional profiling of Bergmann glial cells from mouse cerebellum. PLoS ONE. 2010;5:e9198.

43. Martinez S, Andreu A, Mecklenburg N, Echevarria D. Cellular and molecular basis of cerebellar development. Front Neuroanat. 2013;7:18.

44. Sillitoe RV, Joyner AL. Morphology, molecular codes, and circuitry produce the three-dimensional complexity of the cerebellum. Annu Rev Cell Dev Biol. 2007;23:549-77.

45. Shiotsuki H, Yoshimi K, Shimo Y, Funayama M, Takamatsu Y, Ikeda $\mathrm{K}$, et al. A rotarod test for evaluation of motor skill learning. J Neurosci Methods. 2010;189:180-5.

46. He M, Liu J, Cheng S, Xing Y, Suo WZ. Differentiation renders susceptibility to excitotoxicity in HT22 neurons. Neural Regen Res. 2013;8:1297-306.

47. Herrera F, Martin V, Garcia-Santos G, Rodriguez-Blanco J, Antolin I, Rodriguez C. Melatonin prevents glutamate-induced oxytosis in the HT22 mouse hippocampal cell line through an antioxidant effect specifically targeting mitochondria. J Neurochem. 2007;100:736-46.

48. Roberts TC, Hart JR, Kaikkonen MU, Weinberg MS, Vogt PK, Morris KV. Quantification of nascent transcription by bromouridine immunocapture nuclear run-on RT-qPCR. Nat Protoc. 2015;10:1198-211.

49. Patrone G, Puppo F, Cusano R, Scaranari M, Ceccherini I, Puliti $\mathrm{A}$, et al. Nuclear run-on assay using biotin labeling, magnetic bead capture and analysis by fluorescence-based RT-PCR. Biotechniques 2000;29:1012-4, 6-7.

50. Smale ST. Nuclear run-on assay. Cold Spring Harb Protoc. 2009;2009:pdb.prot5329.

51. Zhang Y, Liu Y, Xu X. Knockdown of LncRNA-UCA1 suppresses chemoresistance of pediatric AML by inhibiting glycolysis through the microRNA-125a/hexokinase 2 pathway. J Cell Biochem. 2018;119:6296-308.

52. Salmena L, Poliseno L, Tay Y, Kats L, Pandolfi PP. A ceRNA hypothesis: the Rosetta Stone of a hidden RNA language? Cell 2011;146:353-8.
53. Yang JH, Li JH, Shao P, Zhou H, Chen YQ, Qu LH. starBase: a database for exploring microRNA-mRNA interaction maps from Argonaute CLIP-Seq and Degradome-Seq data. Nucleic Acids Res. 2011;39:D202-9.

54. Li JH, Liu S, Zhou H, Qu LH, Yang JH. starBase v2.0: decoding miRNA-ceRNA, miRNA-ncRNA and protein-RNA interaction networks from large-scale CLIP-Seq data. Nucleic Acids Res. 2014;42:D92-7.

55. Paraskevopoulou MD, Vlachos IS, Karagkouni D, Georgakilas G, Kanellos I, Vergoulis T, et al. DIANA-LncBase v2: indexing microRNA targets on non-coding transcripts. Nucleic Acids Res. 2016;44:D231-8.

56. Jonas S, Izaurralde E. Towards a molecular understanding of microRNA-mediated gene silencing. Nat Rev Genet. 2015;16: 421-33.

57. Moore MJ, Scheel TK, Luna JM, Park CY, Fak JJ, Nishiuchi E, et al. miRNA-target chimeras reveal miRNA $3^{\prime}$-end pairing as a major determinant of Argonaute target specificity. Nat Commun. 2015;6:8864.

58. Yuzaki M. Two classes of secreted synaptic organizers in the central nervous system. Annu Rev Physiol. 2018;80:243-62.

59. Takeuchi E, Ito-Ishida A, Yuzaki M, Yanagihara D. Improvement of cerebellar ataxic gait by injecting Cbln1 into the cerebellum of cbln1-null mice. Sci Rep. 2018;8:6184.

60. Rong Y, Wei P, Parris J, Guo H, Pattarini R, Correia K, et al. Comparison of Cbln1 and Cbln2 functions using transgenic and knockout mice. J Neurochem. 2012;120:528-40.

61. Uemura T, Lee SJ, Yasumura M, Takeuchi T, Yoshida T, Ra M, et al. Trans-synaptic interaction of GluRdelta2 and Neurexin through Cbln1 mediates synapse formation in the cerebellum. Cell 2010;141:1068-79.

62. Ito-Ishida A, Miura E, Emi K, Matsuda K, Iijima T, Kondo T, et al. Cbln1 regulates rapid formation and maintenance of excitatory synapses in mature cerebellar Purkinje cells in vitro and in vivo. J Neurosci. 2008;28:5920-30.

63. Otsuka S, Konno K, Abe M, Motohashi J, Kohda K, Sakimura K, et al. Roles of Cbln1 in non-motor functions of mice. J Neurosci. 2016;36:11801-16.

64. Nakajima C, Kulik A, Frotscher M, Herz J, Schafer M, Bock HH, et al. Low density lipoprotein receptor-related protein 1 (LRP1) modulates N-methyl-D-aspartate (NMDA) receptor-dependent intracellular signaling and NMDA-induced regulation of postsynaptic protein complexes. J Biol Chem. 2013;288:21909-23.

65. Salto R, Vilchez JD, Giron MD, Cabrera E, Campos N, Manzano $\mathrm{M}$, et al. beta-Hydroxy-beta-methylbutyrate (HMB) promotes neurite outgrowth in Neuro2a cells. PLoS ONE 2015;10:e0135614.

66. Olmsted JB, Carlson K, Klebe R, Ruddle F, Rosenbaum J. Isolation of microtubule protein from cultured mouse neuroblastoma cells. Proc Natl Acad Sci USA. 1970;65:129-36.

67. Sato S, Fujita N, Tsuruo T. Modulation of Akt kinase activity by binding to Hsp90. Proc Natl Acad Sci USA. 2000;97:10832-7.

68. Fuentealba RA, Liu Q, Kanekiyo T, Zhang J, Bu G. Low density lipoprotein receptor-related protein 1 promotes anti-apoptotic signaling in neurons by activating Akt survival pathway. J Biol Chem. 2009;284:34045-53.

69. Hashimoto K, Kano M. Functional differentiation of multiple climbing fiber inputs during synapse elimination in the developing cerebellum. Neuron 2003;38:785-96.

70. Hashimoto K, Kano M. Synapse elimination in the developing cerebellum. Cell Mol Life Sci. 2013;70:4667-80.

71. Kano M, Watanabe T. Developmental synapse remodeling in the cerebellum and visual thalamus. F1000Res. 2019;8:F1000 Faculty Rev-1191. 